\title{
The constitutive modelling \\ of London Clay
}

1 Hoe-Chian Yeow BSC (Hons), PhD, CEng, MICE Technical Director, COWI (formerly Arup Geotechnics), London, UK (corresponding author: hoye@cowi.com)
2 Matthew R. Coop BSc (Eng), DPhil

Professor, University College London, London, UK (formerly Imperial College London)
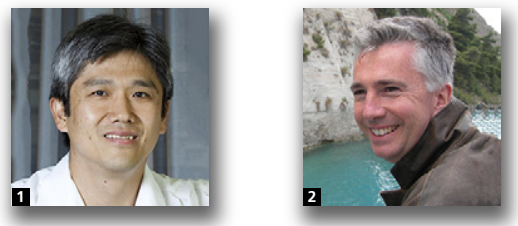

Advances in understanding real soil behaviour, achieved over the past twenty years, and subsequent developments of relevant soil constitutive models, have greatly enhanced the predictive ability of numerical analyses of geotechnical structures. Of particular relevance, especially for serviceability limit state (SLS) design, has been the understanding of soils' small strain behaviour. For the behaviour of London Clay, initially developed models were simple curve-fitting techniques that reproduce stiffness dependence on stress and strain level, which has shown some successes in predicting SLS behaviours. Modelling failure of London Clay is significantly more complex due to its overconsolidated and fissured nature. More recent developments in soil constitutive modelling have therefore tried to encompass most important aspects of clay behaviour within the unified framework of critical state. However, even these advanced models have insufficient features to simulate the behaviour of overconsolidated clays. In this paper, a study has been made, comparing high quality laboratory triaxial data on London Clay with the predictions of two constitutive models, highlighting these deficiencies. It is shown how relatively simple modifications of advanced models, to capture the anisotropy of small strain stiffness and to impose a strength curtailment to represent strain localisation, can significantly improve the predictions of laboratory experiments.

\section{Notation}

$A, m, n$ dimensionless parameters in Equation 1

$E_{\mathrm{h}} \quad$ Young's modulus in horizontal direction

$E_{\mathrm{v}} \quad$ Young's modulus in vertical direction

$G_{0} \quad$ elastic shear modulus

$G_{\mathrm{hh}} \quad$ elastic shear modulus in horizontal plane

$G_{\mathrm{hv}}, G_{\mathrm{vh}}$ elastic shear moduli in vertical plane

$G_{\text {tan }} \quad$ tangent shear modulus

$M \quad$ gradient of critical state line in $q: p^{\prime}$ plane

$N \quad$ specific volume on the isotropic compression line at $p^{\prime}=1 \mathrm{kPa}$

$p^{\prime} \quad$ mean normal effective stress

$p_{\mathrm{a}}^{\prime}, q_{\mathrm{a}} \quad$ stress state at centre of history surface

$p_{\mathrm{b}}^{\prime}, q_{\mathrm{b}} \quad$ stress state at centre of yield surface

$p_{\mathrm{o}}^{\prime} \quad$ half the value of the mean effective stress at the intersection of the current swelling line with the isotropic compression line

$p_{\mathrm{r}} \quad$ reference pressure $=1 \mathrm{kPa}$

$q \quad$ deviatoric stress

$R_{0} \quad$ overconsolidation ratio in terms of $p^{\prime}$

$S \quad$ ratio of the size of the yield surface to that of the history surface mean stress $\left(=1 / 2\left(\sigma_{\mathrm{a}}^{\prime}+\sigma_{\mathrm{r}}^{\prime}\right)\right)$

ratio of the size of the history surface to that of the bounding surface

specific volume

parameters in the plastic potential function parameters in the hardening modulus

ratio of stiffness to overconsolidation in the Brick model

ratio of strength to overconsolidation in the Brick model

intercept of critical state line in $v: \ln p^{\prime}$ plane at $1 \mathrm{kPa}$ deviator strain $\left(=\varepsilon_{\mathrm{a}}-\varepsilon_{\mathrm{r}}\right)$

axial strain

ratio of stiffness at small strain to mean effective stress in the Brick model gradient of swelling line in $\ln v: \ln p^{\prime}$ plane gradient of the isotropic intrinsic compression line in the $\ln v: \ln p^{\prime}$ plane

Poisson ratio

axial effective stress

radial effective stress

angle of shear resistance 


\section{Introduction}

The behaviour of London Clay has recently been the subject of intensive research, much of which was prompted by the construction of Heathrow Terminal 5 (e.g. Gasparre et al., 2007a, 2007b; Hight et al., 2007; Nishimura et al., 2007), or extensive tunnelling projects (e.g. Pantelidou and Simpson, 2007). In parallel with the large amount of new experimental work, an attempt has been made to reassess how London Clay should be modelled within finite-element analyses, which is described in this paper.

The key aspects of the behaviour that have been highlighted by recent research are the role that structure plays in determining the behaviour of London Clay (Gasparre et al., 2007b), the importance of the anisotropy both at small and large strain levels (Gasparre et al., 2007a; Nishimura et al., 2007), and the interaction of recent stress history, creep and rates of loading in determining the stiffness at small strains (Gasparre et al., 2007a; Sorensen et al., 2007). The work also highlighted significant variation in properties between the various sub-units (Hight et al., 2007; Pantelidou and Simpson, 2007).

Structure was found to play a role in the behaviour of London Clay at several scales. Intact, unfissured samples were found to be significantly stronger than equivalent reconstituted samples at similar stress levels and void ratios. In contrast, the effect on stiffness was much smaller, the stiffnesses of the intact soil generally being slightly lower than the reconstituted soil after accounting for the effects of void ratio. The greater strength could only be attributed to some form of structure, perhaps a bonding, even if it was not possible to see any widespread interparticle cement in the scanning electron micrographs (SEMs) that were examined. The SEMs did, however, show significant differences in the micro-fabric, with a denser and more orientated packing at greater depths, which corresponded to an increase in the anisotropy of stiffness. Figure 1 illustrates the anisotropy of elastic stiffnesses measured, with significantly higher horizontal Young's moduli, $E_{\mathrm{h}}$, than vertical, $E_{\mathrm{v}}$, and also greater shear moduli in the horizontal plane, $G_{\mathrm{hh}}$, than in the vertical, $G_{\mathrm{vh}}$ and $G_{\mathrm{hv}}$. While the values of the various stiffnesses increase with depth, both as a result of the increased stress level and with the change in sub-unit, the anisotropy ratio defined in terms of Young's modulus also increases, from a little under 2 at the top of the London Clay to nearly 3 at $30 \mathrm{~m}$ depth (here the depths are measured from the top of the stratum). In contrast, the ratio of shear moduli remains about constant.

Perhaps even more significant than the micro-fabric was the macro-fabric, especially the natural fissures within the London Clay, which were found to occur throughout its depth, and which were the principal cause of a pronounced anisotropy of strength (Nishimura et al., 2007). The effect of the natural fissures on triaxial undrained shear strengths depended first on whether one or more was present in a sample, which is related to sample size and fissure spacing, and second on the

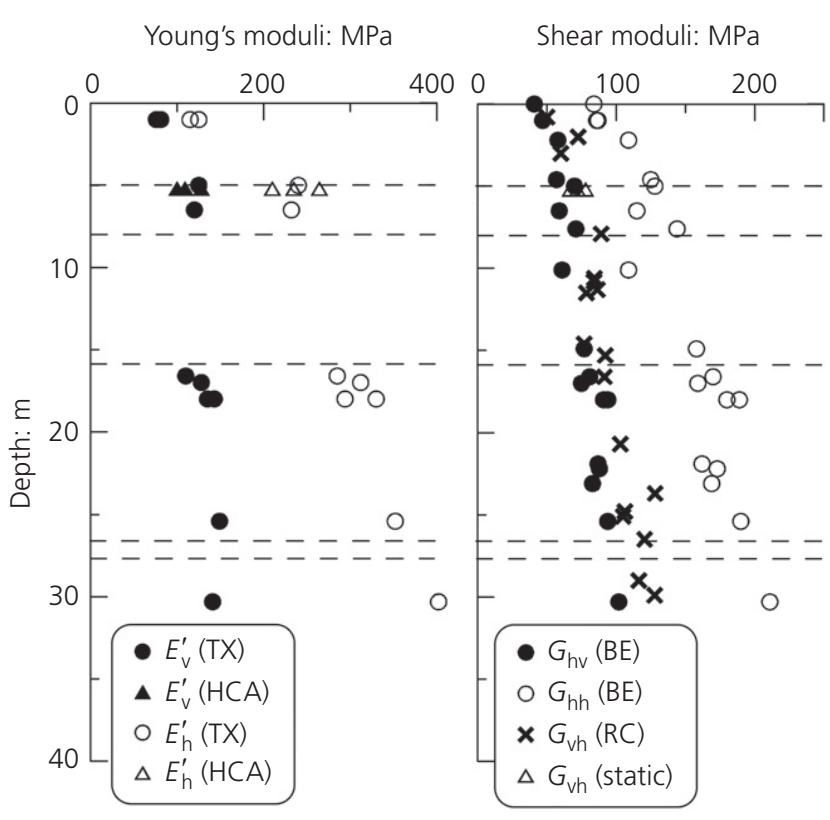

Figure 1. Anisotropy of elastic stiffness (Gasparre et al., 2007a)

orientation of those fissures. As illustrated in Figure 2, a fissure orientated close to the plane of maximum stress obliquity has the effect of curtailing significantly the peak strength, when compared to a sample in which a new shear plane is formed during shearing as a result of strain localisation. From an analysis of the Mohr's circles for the 'postrupture' states (Burland, 1990) immediately after the peak strength, using the measured shear plane inclinations, it was found that the mobilised angle of shearing resistance on the new shear planes formed due to localisation, and that on preexisting shear planes as part of the natural fabric, were similar. Both were also close to the critical state angle of shearing resistance measured for reconstituted samples that failed without localisation. This indicates that, in contrast to the much larger and less numerous tectonic shears in London Clay that have reached their residual strength (Chandler et al., 1998), large displacements have not been mobilised on the fissures.

Following the scheme of Jardine (1995), the yielding behaviour of London Clay was characterised by kinematic yield surfaces, a Y1 surface corresponding to the yield at the end of a linear elastic range of behaviour, and a Y2 surface corresponding to a change in the direction of the plastic strain increment vector during shearing (Gasparre et al., 2007a). The size of these surfaces was found to be simply a function of stress level and did not vary between sub-units. While the diameter of the Y1 surface was in the approximate range of $2-4 \mathrm{kPa}$, that of the Y2 envelope was around $15-30 \mathrm{kPa}$. An alternative description of the yielding behaviour of soils is to define a 'history' surface instead of the more empirical Y2 surface, which is the basis of models that incorporate the effects of recent stress history (e.g. Stallebrass and Taylor, 1997). The history surface is defined 


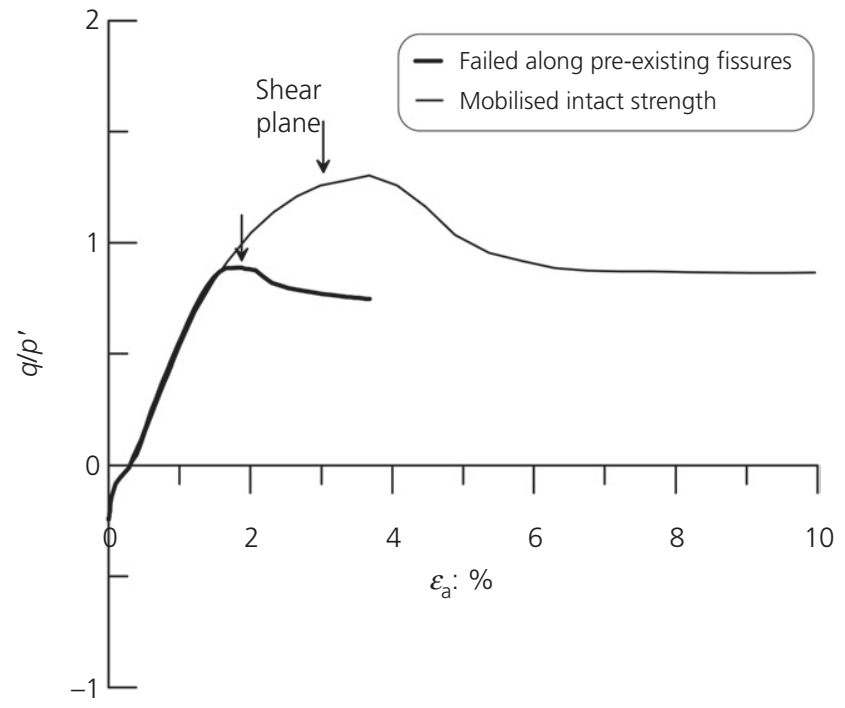

Figure 2. Typical stress-strain curves for undrained shearing in compression (Gasparre et al., 2007b)

for overconsolidated clays as the locus of points where the stiffness is no longer a function of the previous loading history. If identical loading paths are imposed on identical samples, but different approach paths are used to the initial state prior to loading, then the point where the stiffness-strain decay curves converge is when the history surface is engaged. Although this was not explicitly measured by Gasparre et al. (2007a), it was observed to be much larger than the Y2 surface. For a range of soils, including London Clay, Clayton and Heymann (2001) had found that the effects of recent stress history could be erased by allowing very long creep periods prior to shearing. However, the approach paths that they had used were much shorter and imposed much smaller strains than those used by Atkinson et al. (1990) in establishing the existence of recent stress history. This was partly because Clayton and Heymann (2001) were trying to avoid any effects of destructuration of the natural samples that they were testing, since they were applying multiple load stages to single samples. Gasparre et al. (2007a) confirmed that creep could indeed erase the effects of recent stress history for intact samples of London Clay, providing the approach paths remained within the Y2 envelope of the soil, but that once Y2 had been engaged, there would always be a recent stress history effect, at least for the creep periods of up to $10 \mathrm{~d}$ that they allowed.

\section{Constitutive models for natural clays}

Of the simple constitutive models, which deal mainly with nonlinear small strain behaviour of clays, those of Simpson et al. (1979), Jardine et al. (1986) or Simpson (1992) have been the most successful in the analyses of serviceability limit states for structures in both London Clay and other stiff clays (e.g. Jovicic et al., 2006). However, these models lack a firm theoretical framework and are usually coupled with other plastic models.
A number of advanced constitutive models have been developed in recent years with the intention of improving the modelling of natural stiff clays. They can be broadly classified into frameworks of kinematic hardening (e.g. Mroz et al., 1978), bounding surface (e.g. Dafalias \& Herrmann, 1980), or hierarchical surfaces (e.g. Desai et al., 1986) plasticity. From this group of models, this paper concentrates on the application of those developed within the framework of kinematic hardening plasticity. Globally, such a model comprises the state boundary surface (which is usually the ellipse of the modified Cam Clay (MCC) model), within which there can be a number of nested smaller surfaces or 'bubbles' that follow prescribed rules for their interaction. The smallest surface is usually the boundary of elasticity (the Y1 surface observed in experiments described above) and elasto-plastic behaviour is engaged as soon as the stress state engages this surface. This is one of the main advantages of this type of model in terms of simulating real soil behaviour, compared to the MCC type models where plasticity is invoked only when the stress state reaches the state boundary surface. In addition, these models can automatically account for reversals in the stress path direction and for the effects of recent stress history.

Since the postulation by Mroz et al. (1978), the main developments of this framework for geotechnical applications were a single kinematic surface model of Al-Tabbaa and Muir Wood (1989) and the model of Stallebrass and Taylor (1997) with two kinematic surfaces inside the state boundary surface. The effects of clay structure were taken into account in similar models proposed by, for example, Kavvadas and Amorosi (2000), Rouainia and Muir Wood (2000) and Gajo and Muir Wood (2001), of which some also account for the recent stress history effect below the state boundary surface (e.g. Baudet and Stallebrass, 2004). They generally have some form of state boundary surface that is enlarged relative to that of the reconstituted clay, the size of which may be related to the sensitivity of the soil. The boundary surface then shrinks with plastic volumetric strain, shear strain or some combination of the two. A number of models have also been developed to cope with anisotropy of strength arising from the natural structure (e.g. Kavvadas and Amorosi, 2000; Koskinen et al., 2002), but few can also model the anisotropy of small strain behaviour that is typical of London Clay (e.g. Whittle, 1993).

Despite advantages in modelling real soil behaviour mentioned above, kinematic hardening models typically have a serious deficiency in modelling the strength of overconsolidated clays, for which the initial stress state is on the dry side of critical. This is a common problem in critical state type models based on the MCC model, and arises for two reasons. One reason is that the elliptical MCC state boundary surface reaches unrealistically high $q / p^{\prime}$ ratios on the dry side, although, as Stallebrass and Taylor (1997) showed, the allowance of plasticity to develop before the state boundary surface is engaged tends to reduce the stress ratios achieved. However, of much 
greater importance is the tendency within these models to follow a strongly dilative path as the state moves towards the critical state line. While Atkinson (2000) showed that for fast loading rates the true critical state could be reached, for high overconsolidation ratio (OCR) plastic clays and under more typical loading rates, internal drainage within the soil permits strain localisation and the strength to be severely curtailed. None of these models deals expressly with the effects of strain localisation, either on new shear planes developed during shearing or on the fissures pre-existing as part of the natural fabric of the soil. It might be expected that this would limit their effectiveness in modelling boundary value problems in London Clay.

Gasparre et al. (2007b) found that structure has a well-defined effect on the strength and compressibility of London Clay and a lesser effect on shear stiffness, and that it is also responsible for a significant anisotropy of stiffness and strength. However, they also found that its effects are relatively stable and do not break down rapidly with straining, particularly in compression. The strength during shearing was dominated by the effects of strain localisation, which masked any effects of breakdown of structure. It was therefore decided for the analyses undertaken here, that it was more important to account for other features of the soil behaviour, and in particular the effects of localisation and anisotropy. Consequently, as the base constitutive models for this study, 'Brick' (Simpson, 1992) and the recent stress history kinematic hardening model M3SKH of Grammatikopoulou et al. (2006), were used to simulate recent high-quality test data, and the first aim of this paper is to compare and contrast how the two base models manage to model these data using a single element simulation for each. These comparisons suggested how simple improvements could be achieved, particularly for the 'bubble model', to account for the effects of strain localisation and anisotropy of small strain stiffness, and a second set of comparisons then highlights how these improve the predictions made.

\section{The kinematic surface model M3SKH}

The model of Grammatikopoulou et al. (2006) is based on the 3SKH (three-surface kinematic hardening) model of Stallebrass and Taylor (1997). Here it will be referred to as modified 3SKH, or M3SKH, as it contains some improvements to the original formulation. As in the original 3SKH model, the state boundary surface reduces to the MCC ellipse in the $q: p^{\prime}$ plane, with nested elliptical and kinematic Y1 and history

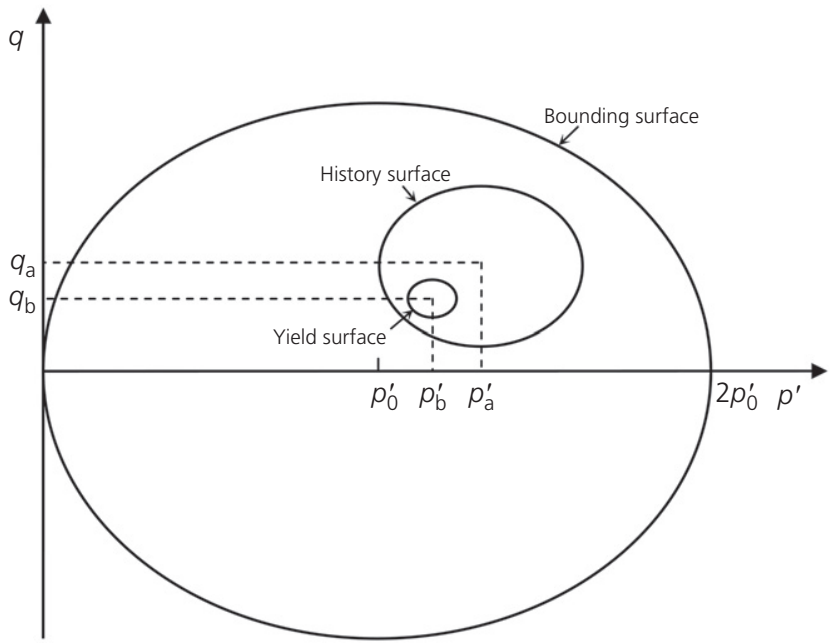

Figure 3. The 3SKH model (after Stallebrass and Taylor, 1997)

surfaces (Figure 3). The model is fully developed for generalised three-dimensional (3D) stress conditions and implemented in the finite-element code ICFEP (Potts and Zdravkovic, 1999). Its first improvement is the implementation of the variety of shapes for the yield and plastic potential surfaces (e.g. Mohr-Coulomb hexagon, Matsuoka-Nakai, or Lade surfaces), which can simulate better soil failure compared to the circular shapes of the original formulation. The model also incorporates a different hardening modulus, which results in a smooth elasto-plastic transition, compared to the original formulation where a sudden drop in stiffness occurs once plasticity is engaged.

The set of parameters used with the M3SKH model in this study was largely based on those chosen by Grammatikopoulou et al. (2006), the values of which are given in Table 1 . These parameters were selected after numerous sensitivity analyses with a credible range of the parameters derived from the laboratory tests by Gasparre (2005). The input parameters are defined as follows

\footnotetext{
$\lambda^{*}$ slope of the isotropic normal compression line in $\ln v-\ln p^{\prime}$ space

$\kappa^{*} \quad$ slope of the swelling line in $\ln v-\ln p^{\prime}$ space for a stress path that lies entirely within the kinematic yield surface

$T$ ratio of the size of the history surface to that of the bounding surface
}

\begin{tabular}{ccccccccccccc}
\hline $\mathrm{OCR}^{\mathrm{a}}$ & $\lambda^{*}$ & $\kappa^{*}$ & $A$ & $n$ & $m$ & $\phi^{\prime}$ & $Y_{\mathrm{p}}$ & $Z_{\mathrm{p}}$ & $T$ & $S$ & $\alpha_{1}$ & $\alpha_{2}$ \\
\hline $6-19$ & 0.09 & 0.03 & 590 & 0.28 & 0.87 & $22.5^{\circ}$ & 0.0 & 1.0 & 0.3 & 0.02 & 6 & 35
\end{tabular}

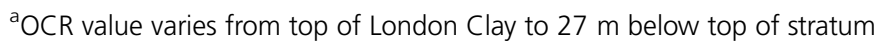

Table 1. Input parameters for the M3SKH model 


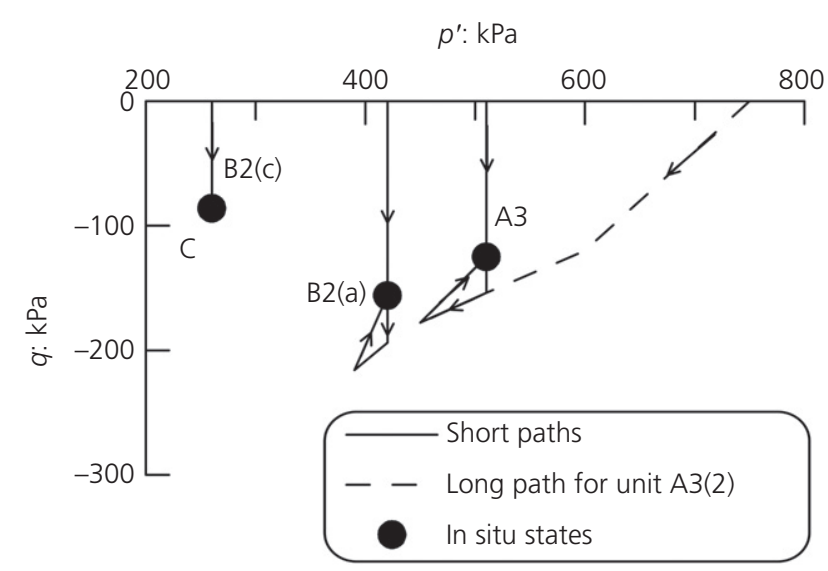

Figure 4. Approach paths for the triaxial tests (after Gasparre et al., 2007a)

$S$ ratio of the size of the yield surface to that of the history surface

$\alpha_{1}, \alpha_{2}$ parameters in the hardening modulus

$N$ specific volume on the isotropic compression line at $p^{\prime}=1 \mathrm{kPa}$

$Y_{\mathrm{p}}, Z_{\mathrm{p}}$ parameters in the plastic potential function; the choice in Table 1 ensures circular shape in deviatoric plane

$\phi^{\prime}$ angle of shearing resistance; ensures Mohr-Coulomb hexagon for the yield surface in deviatoric plane.
The model further incorporates the small strain stiffness dependence on stress level proposed by Viggiani and Atkinson (1995) for saturated clays, which was based on initial work by Wroth and Houlsby (1985) and Hardin and Black (1966) on sands

1. $\frac{G_{0}}{p_{\mathrm{r}}}=A\left(\frac{p^{\prime}}{p_{\mathrm{r}}}\right)^{n} R_{0}^{m}$

where $p_{\mathrm{r}}$ is reference pressure; $G_{0}$ is the elastic shear modulus, assuming isotropy; $R_{0}$ is the overconsolidation ratio defined in terms of $p^{\prime}$; and $A, m$ are $n$ are material parameters. The bulk modulus, derived from the linear relationship between the volumetric strain and $\log$ mean effective stress, is simply proportional to $p^{\prime}$. This elastic model may be valid for purely isotropic stress paths, but it was shown by Zytynski et al. (1978) and Lade and Nelson (1987) to violate energy conservation when following different stress paths. Others have shown later that a rigorous derivation of the elastic compliance matrix should lead to coupling between the volumetric and shear deformations, even for an isotropic material (e.g. Einav and Puzrin, 2004; Houlsby et al., 2005). This implies that the shear and bulk moduli depend on both the mean effective stress and the stress ratio. Experimental evidence, however, seems to indicate that the dependence on the latter may be small at low stress ratios (e.g. data from Rampello et al., 1997; Viggiani and Atkinson, 1995). This coupling, leading to some sort of stress-induced anisotropy, is different from that used to

\begin{tabular}{|c|c|c|c|c|}
\hline Unit & $\begin{array}{l}\text { Sample } \\
\text { name }^{a}\end{array}$ & $\begin{array}{l}\text { Diameter: } \\
\mathrm{mm}\end{array}$ & $\begin{array}{l}\text { Sample depth: } \\
\text { mBGL }\end{array}$ & Description of stress path \\
\hline$B_{2(a)}$ & $26 \cdot 3 \mathrm{iUC}^{\mathrm{b}}(\mathrm{I})$ & 100 & $26 \cdot 25$ & $\begin{array}{l}\text { Isotropic unloading from } 420 \mathrm{kPa} \text { to } 70 \mathrm{kPa} \text {, reloaded to } 235 \mathrm{kPa} \text { before } \\
\text { shearing undrained to failure in compression }\end{array}$ \\
\hline$B_{2(a)}$ & $25 \cdot 4 a U E^{b}(\mid 17)$ & 100 & $25 \cdot 4$ & $\begin{array}{l}\text { Isotropic loading from } 315 \mathrm{kPa} \text { to } 700 \mathrm{kPa} \text {, unloaded to } 440 \mathrm{kPa} \text { and shear } \\
\text { undrained to failure in extension }\end{array}$ \\
\hline$A_{3(2)}$ & $\begin{array}{l}33 \cdot 5 \mathrm{gkUC} C^{b} \\
(137)\end{array}$ & 38 & $24 \cdot 3$ & $\begin{array}{l}\text { Isotropic unloading from } 510 \mathrm{kPa} \text { to } 420 \mathrm{kPa} \text {, short geological stress history } \\
\text { followed by } k_{0} \text { compression to } p^{\prime}=975 \mathrm{kPa} \text { and } q=485 \mathrm{kPa} \text { before shearing } \\
\text { to failure undrained }\end{array}$ \\
\hline$B_{2(a)}$ & $31 \cdot 4 g U E^{b}$ & 100 & $31 \cdot 5$ & $\begin{array}{l}\text { Isotropic loading from } 200 \mathrm{kPa} \text { to } 510 \mathrm{kPa} \text {, short geological history to } \\
p^{\prime}=510 \mathrm{kPa} \text { and } q=-125 \mathrm{kPa} \text { before shearing to failure undrained in } \\
\text { extension }\end{array}$ \\
\hline$B_{2(a)}$ & $25 \mathrm{gUC}$ & 100 & $25 \cdot 0$ & $\begin{array}{l}\text { Isotropic loading from } 350 \mathrm{kPa} \text { to } 420 \mathrm{kPa} \text {, short geological history to } \\
p^{\prime}=420 \mathrm{kPa} \text { and } q=-155 \mathrm{kPa} \text { before shearing to failure undrained in extension }\end{array}$ \\
\hline$B_{2(a)}$ & 23.6iUC & 38 & $23 \cdot 6$ & Isotropic loading from $400 \mathrm{kPa}$ to $1285 \mathrm{kPa}$ before shearing to failure undrained \\
\hline$C$ & 11.7iUC & 100 & $11 \cdot 7$ & $\begin{array}{l}\text { Consolidate to saturate at isotropic stress } 125 \mathrm{kPa} \text { before shearing to failure } \\
\text { undrained }\end{array}$ \\
\hline
\end{tabular}

aSample name annotated by depth of sample and nature of the test path adopted

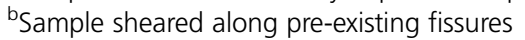

$i$, isotropic compression; $k, k_{0}$ consolidation; $g$, shortcut along the geological history stress path; UC, undrained compression; UE, undrained extension

Table 2. Stress paths for all samples used in the back analyses 


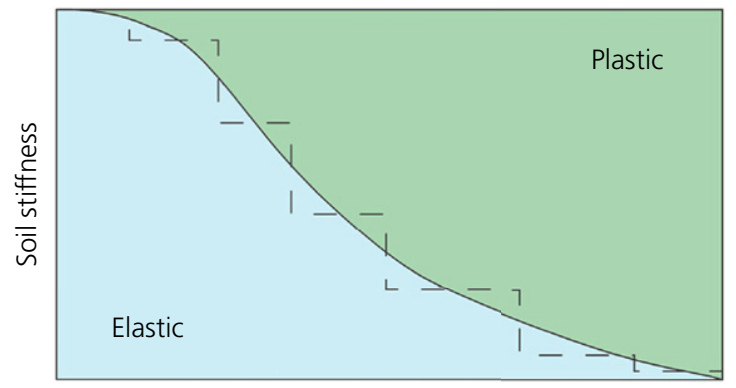

$\log ($ strain)

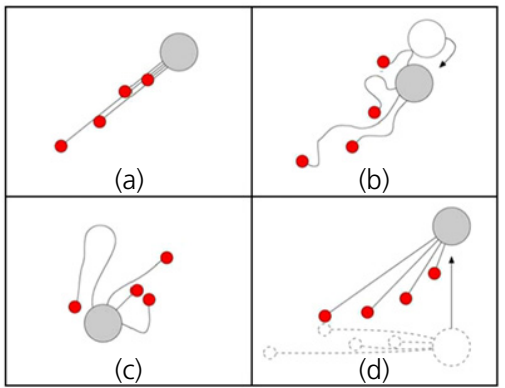

'Man'•'Brick'
Figure 5. The Brick model (Simpson, 1992): (a) Bricks line up behind man when he continues in the same direction; (b) Bricks initially do not moves when the man turns back; (c) Bricks with shorter strings start to move follow by those with longer strings; (d) Bricks initially move in the same direction when man turns $90^{\circ}$ simulate inherent anisotropy (e.g. Graham and Houlsby, 1983), which will be modelled here.

The M3SKH model can simulate the overall geological stress history of London Clay, as shown by Grammatikopoulou et al. (2006), to reproduce current profiles of OCR and coefficient of earth pressure at rest, $K_{0}$. However, this global history can also be simulated by specifying OCR as model input parameter and defining the $K_{0}$ in the initial stresses, and this is the approach adopted here. In order to mimic the effects of recent stress history, the approach paths to the initial state for shearing that were applied by Gasparre et al. (2007a, 2007b) to the sample in the apparatus were also modelled in the simulations. In the laboratory tests, some of the samples were isotropically loaded or unloaded to the desired initial $p^{\prime}$. Other tests followed the recent geological history by the paths for each sub-unit shown in Figure 4. For these tests, a stress path mimicking a 'short' geological history has been adopted. Where appropriate, a small amount of reloading was introduced representing the deposition of the Terrace Gravels at the location of Heathrow T5. Details of the stresses on the approach paths for the various samples are given in Table 2, and details of the triaxial test results and procedures are given by Gasparre et al. (2007a, 2007b) and Gasparre (2005).

\section{4. 'Brick' model}

Within the Brick model (Simpson, 1992) the memory of the recent stress history is analogous to a man walking along with a series of bricks towed behind him on strings of different lengths (see Figure 5) in a strain space. As he changes direction the various strings will become slack until the bricks re-engage, the strings line up behind the man and the strings become taut again. In the model, the movement of each brick directly represents the development of plastic strain for a fixed proportion of the material. Thus, when all the strings are loose (Figure 5(b)), the behaviour is entirely elastic; when all the strings are taut and the bricks are lined up behind the man and normal to the volumetric strain axis, the behaviour is entirely

\begin{tabular}{ll} 
Strain & $G / G_{\max }$ \\
\hline $3.04 \times 10^{-5}$ & 0.92 \\
$6.09 \times 10^{-5}$ & 0.75 \\
$1.014 \times 10^{-4}$ & 0.53 \\
$1.211 \times 10^{-4}$ & 0.29 \\
$8.2 \times 10^{-4}$ & 0.13 \\
$1.71 \times 10^{-3}$ & 0.075 \\
$3.52 \times 10^{-3}$ & 0.044 \\
$9.69 \times 10^{-3}$ & 0.017 \\
$2.223 \times 10^{-2}$ & 0.0035 \\
$6.46 \times 10^{-2}$ & 0
\end{tabular}

$\lambda^{*}=0.1, \kappa^{\star}=0.02$ and $l=0.0019$

$v=0 \cdot 2, \beta_{\mathrm{G}}=4 \cdot 0, \beta_{\phi}=2 \cdot 0, n=1$

Table 3. 'Brick' soil model input parameters

plastic. The program therefore models the recent stress history by the disposition of memory points defining the approach loading path. The stiffness decay curve is essentially a model parameter, and if the tangent shear modulus $G_{\tan }$ is normalised by the mean stress $s^{\prime},\left(\sigma_{x}^{\prime}+\sigma_{y}^{\prime}\right) / 2$, and is then plotted against shear strain, $\gamma$, then the area under the curve is equal to $\sin \phi^{\prime}$. It is the string lengths that then define the shape of the decay curve. Brick was developed by Simpson (1992) specifically to model natural London Clay, even if it does not expressly account for the effects of structure. It has also been used successfully by Jovicic et al. (2006) to model a stiff North Sea clay, which also had a significant influence of structure on its behaviour.

The Brick parameters used to model the London Clay are given in Table 3. The parameters $\lambda^{*}$ and $\kappa^{*}$ define the compression behaviour in a similar, but not identical manner to the more usual $\lambda$ and $\kappa$. These parameters are the gradients of the compression and swelling lines in the $\ln V-\ln p^{\prime}$ space. The parameter $\imath$ defines the ratio of elastic stiffness to $p^{\prime}$, and $v$ is the Poisson ratio. Brick assumes a linear relationship between 


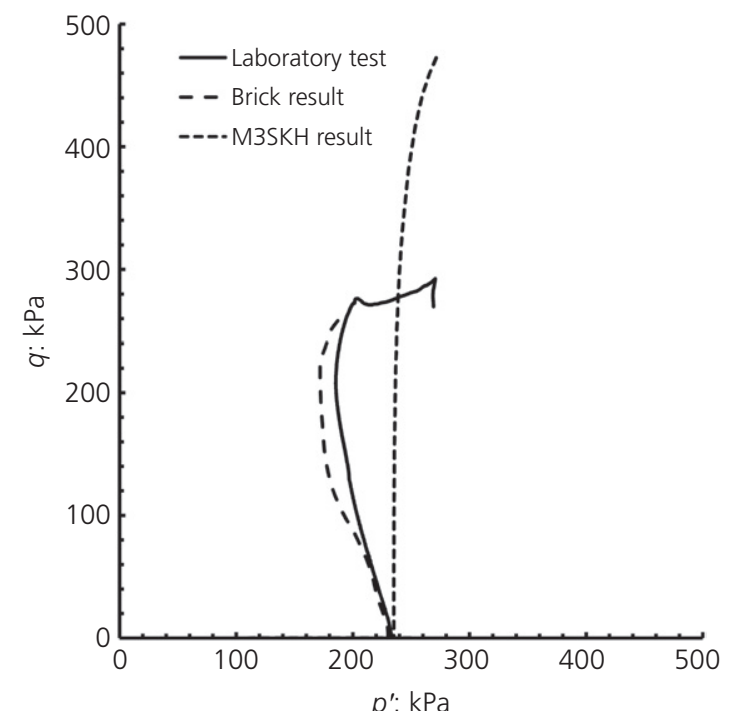

(a)

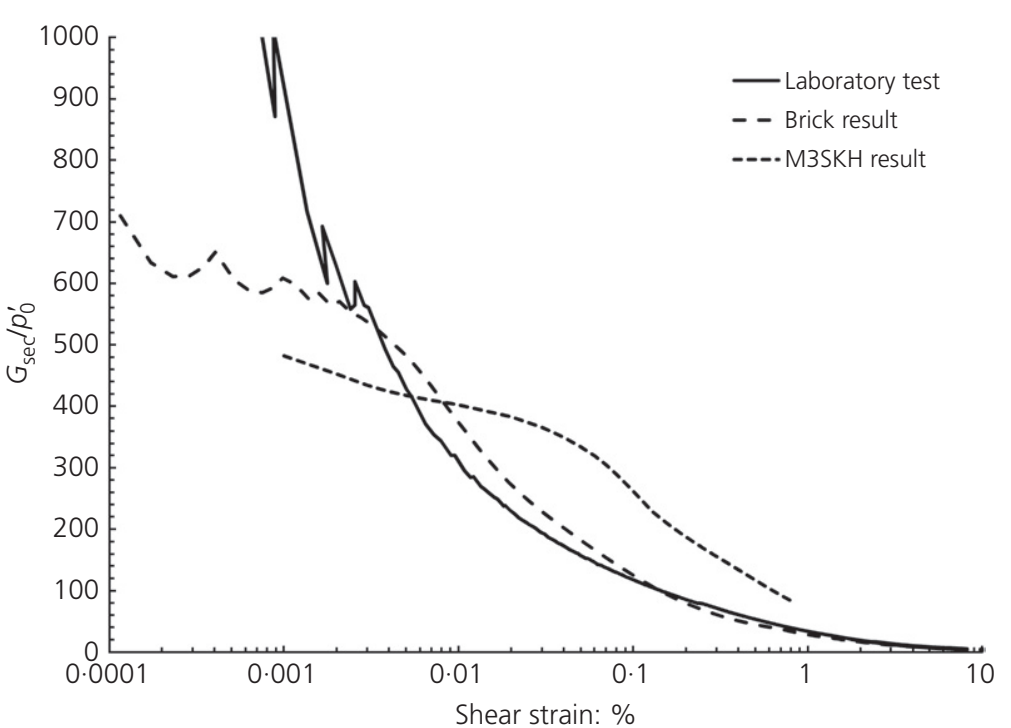

(b)

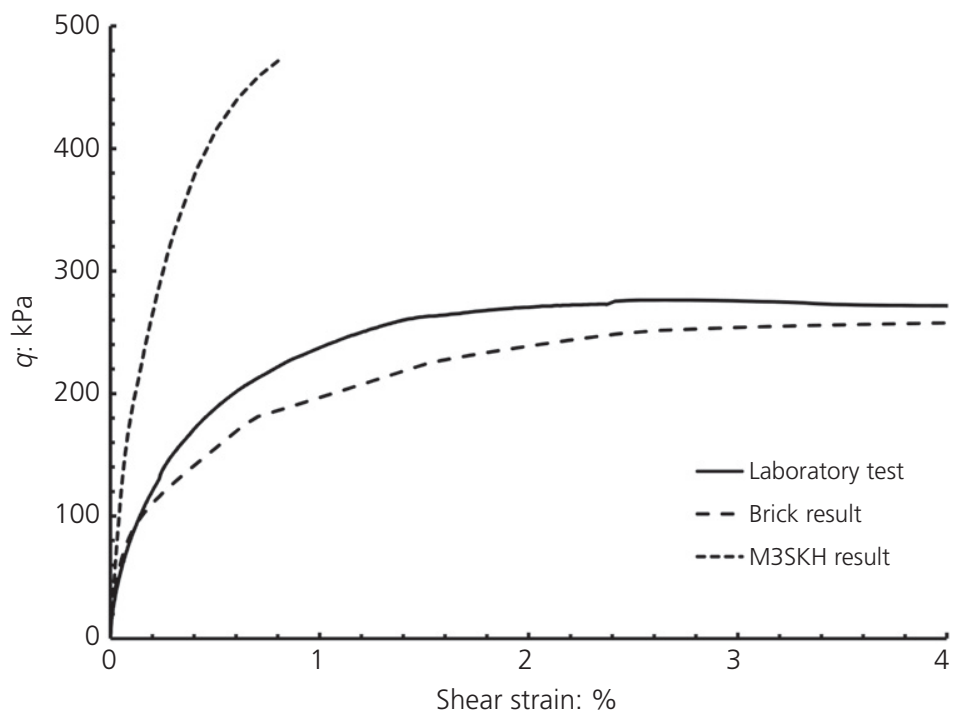

(c)

Figure 6. Comparison of computed stress path and stiffness from Brick, M3SKH and laboratory test results for undrained shearing in compression from an isotropic initial state: (a) stress path under triaxial compression test; (b) stiffness degradation curve under triaxial compression test; and (c) shearing behaviour under triaxial compression test stiffness and the logarithm of OCR, and the parameters $\beta_{\mathrm{G}}$ and $\beta_{\Phi}$ control this relationship. Simpson (2000, personal communication) had separated the parameter $\beta$ into two components, $\beta_{\mathrm{G}}$ and $\beta_{\Phi}$, which he found modelled better the influence of overconsolidation for London Clay.

For the Brick model, rather than specifying an OCR, the complete geological history of the soil must be replicated in the analysis; here a maximum past vertical stress of $2 \mathrm{MPa}$ was used followed by erosion and redeposition, where appropriate. This then defines the initial conditions of the soil in terms of in situ stresses and positions of the bricks after following that history. However, as will be discussed later, in some cases this means that the initial stress state is not the same as that used in the triaxial tests, because $K_{0}$ is often underestimated, and so that initial state has then been adjusted to reflect the stress state used in the laboratory tests prior to simulating the undrained shearing.

\section{Comparisons between numerical predictions and triaxial test results using the base models}

A series of numerical simulations were carried out using finite-element programs with both the M3SKH and Brick 


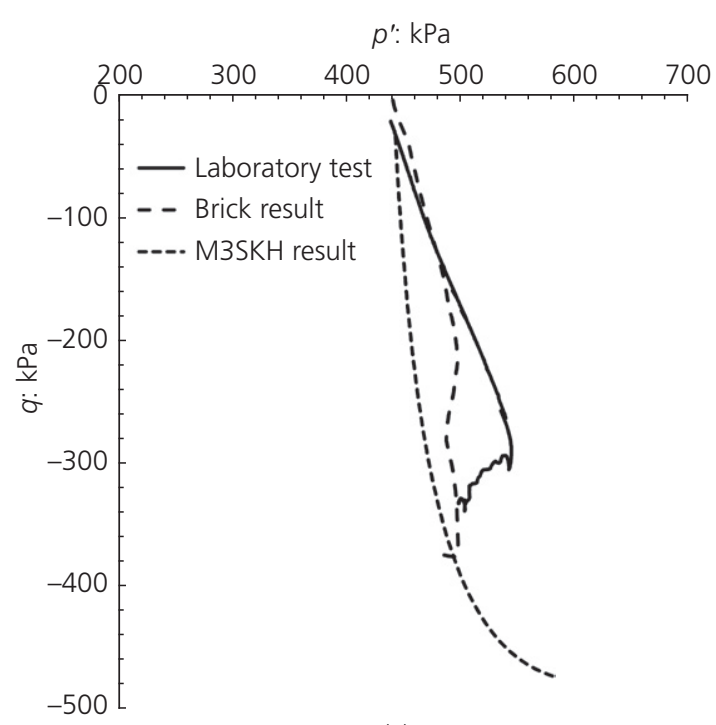

(a)

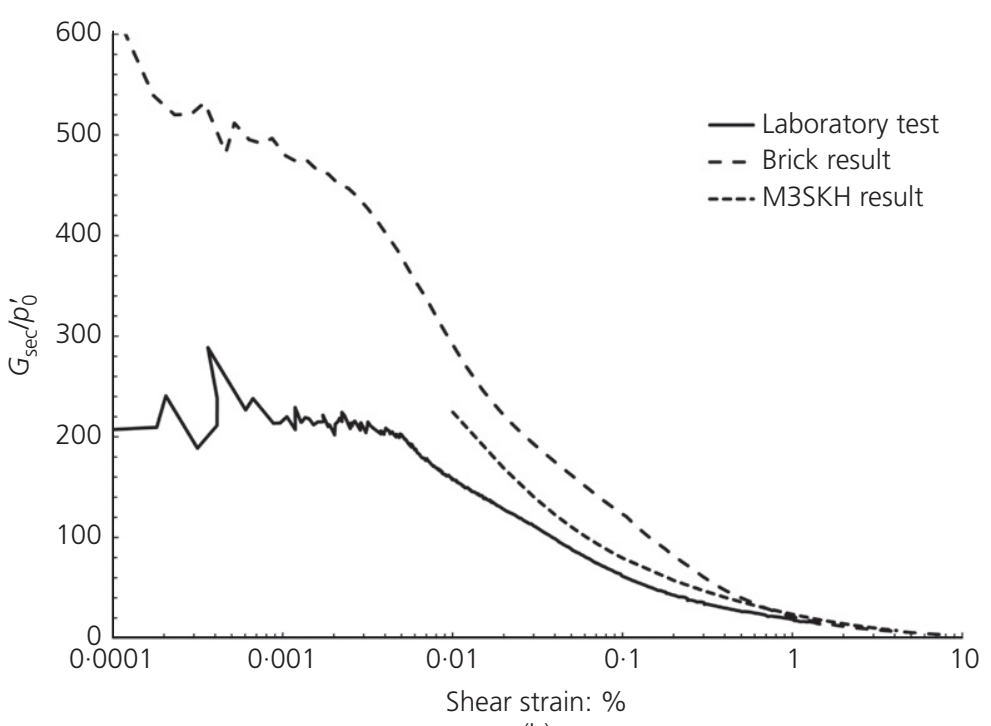

(b)

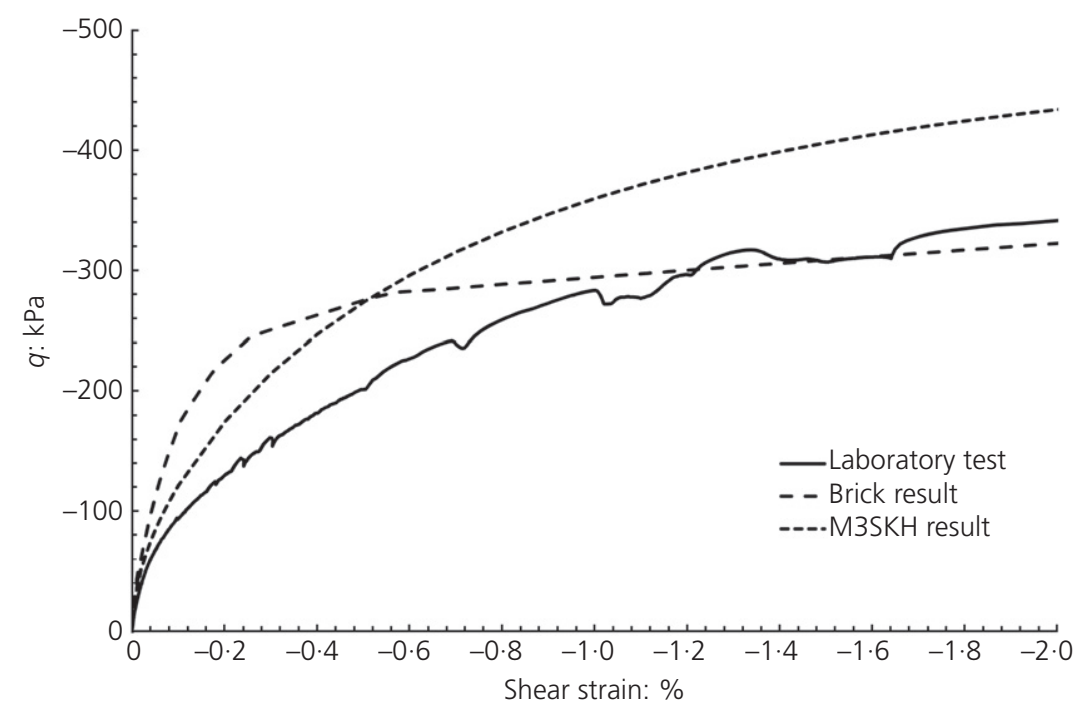

(c)

Figure 7. Comparison of computed stress paths and stiffness from Brick, M3SKH and laboratory test results for undrained shearing in extension: (a) stress path under triaxial extension test; (b) stiffness degradation curve under triaxial extension test; (c) shearing behaviour under triaxial extension test models to investigate the behaviour of the London Clay under different stress, stress path and modes of loading conditions. These predictions were compared against high-quality laboratory triaxial tests undertaken on the London Clay as part of the $\mathrm{PhD}$ research undertaken by Gasparre (2005) (see Gasparre et al., 2007a, 2007b). The samples were all rotary cored and generally of $100 \mathrm{~mm}$ dia. The depth of each sample below the ground surface is indicated by the sample number, the depth below the top of the London Clay being $6 \mathrm{~m}$ less. All of the samples came from unit $B_{2(a)}$, with the exception of sample $11 \cdot 7 \mathrm{iUC}$, which was from a shallower unit $B_{2(\mathrm{c})}$.
Figure 6 shows the Brick and M3SKH predictions of a simple undrained loading from an isotropic initial state of a rotary cored sample from a depth of $26.3 \mathrm{~m}$ below ground level (sample 26.3iUC). From its initial mean effective stress, $p^{\prime}=\left(\sigma_{1}^{\prime}+2 \sigma_{2}^{\prime}\right) / 3$, on setting up in the apparatus of $420 \mathrm{kPa}$ the sample was unloaded isotropically to $p^{\prime}=70 \mathrm{kPa}$ and then reloaded to $p^{\prime}=234 \mathrm{kPa}$. It had therefore not been subjected to the complex approach paths of Figure 4. Observation of the shear plane angle within the sample indicated that this sample had failed on a pre-existing fissure. In both simulations the soil was assumed to be isotropic, so the inclination of the stress 


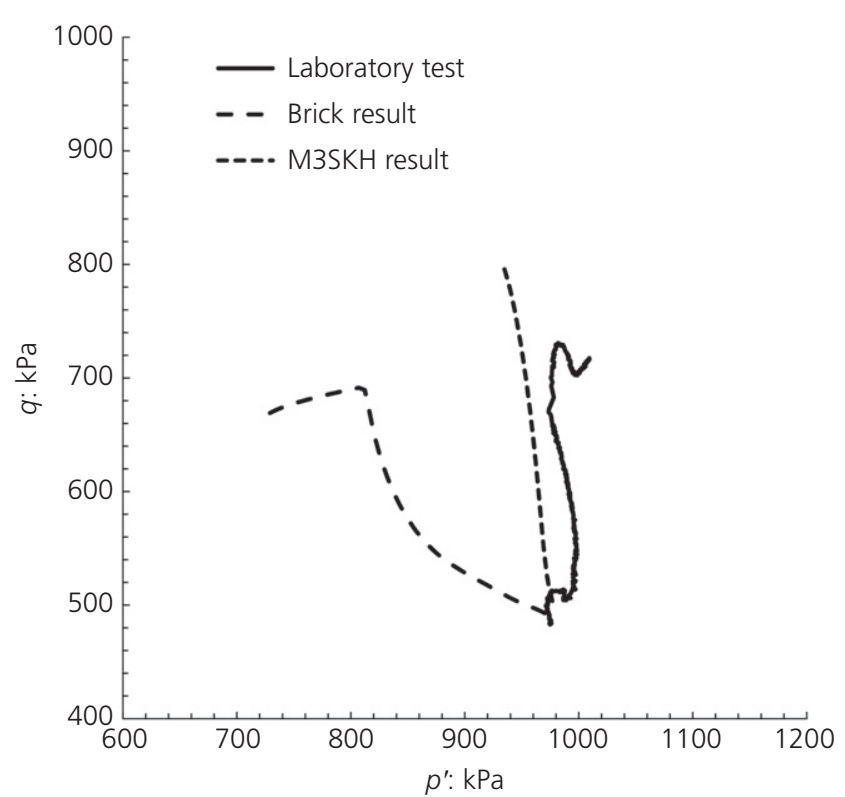

Figure 8. Example predictions for a case when the initial state is closer to the bounding surface in compression

path from Brick must result from the recent stress history. It is interesting that in this respect the M3SKH predictions of the stress path direction, stiffness and strength are poor. The stress path for M3SKH is cut off here at a strain of about $1 \%$ and at larger strains it would follow a dilative direction towards still higher strengths at the critical state. In contrast, for Brick the stress path simply stops when a limiting $\phi^{\prime}$ is reached, so that the strength is very similar to the actual test data simply because the stress path direction was well predicted. The stiffness degradation predicted by the Brick model is also comparable to the test data.

In Figure 7 a similar comparison is made for shearing in extension from an isotropic initial state, again with isotropic soil models. The sample, $25 \cdot 4 \mathrm{aUE}$, had been isotropically compressed from the initial $p^{\prime}$ of $313 \mathrm{kPa}$ to $700 \mathrm{kPa}$ and then swelled to $442 \mathrm{kPa}$. It again failed on a pre-existing fissure. The stress path direction is better in this case for M3SKH, although Brick again produced slightly more inclination in the stress path, possibly attributable to the effect of recent stress history. The stiffness produced by the M3SKH model is closer than the Brick predictions, but again the main problem is in the strength, with the stress path again been curtailed, at $4 \%$ in this case. During the laboratory tests, both the above samples failed on pre-existing fissures.

In Figures 8 and 9 two examples are given where the initial state is closer to the bounding surface. In Figure 8 sample $24 \cdot 3 \mathrm{gkUC}$ had been sheared following a drained $K_{0}$ compression path from the initial state to higher stress levels with $p^{\prime}$ of $975 \mathrm{kPa}, q=485 \mathrm{kPa}$. This was a $38 \mathrm{~mm}$ dia. sample that

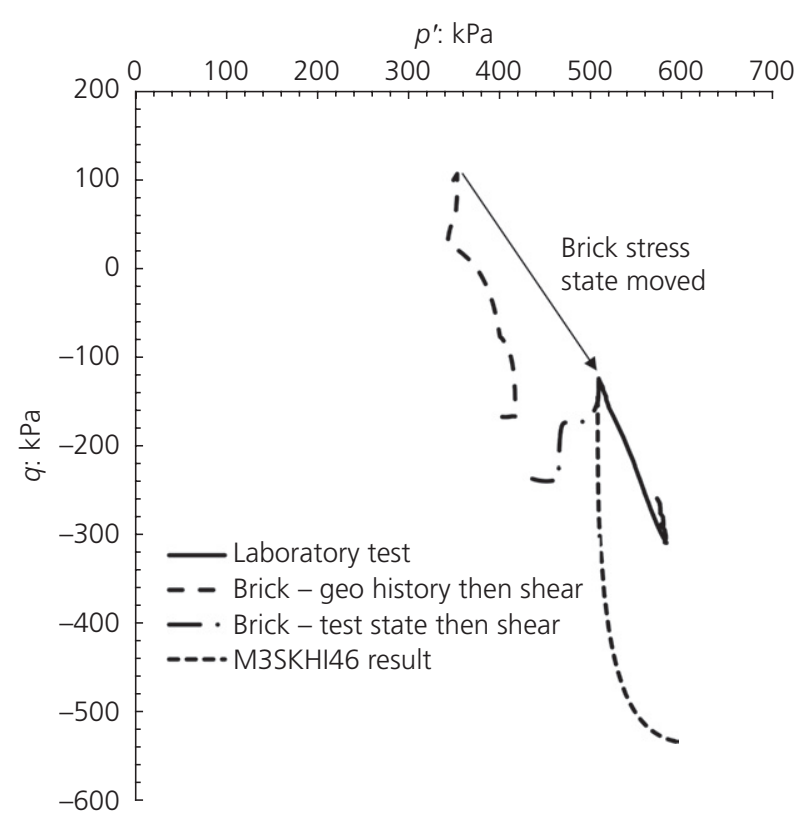

Figure 9. Example predictions for a case when the initial state is closer to the bounding surface in extension

failed on a pre-existing fissure. Sample 31.4gUE in Figure 9 had followed the short geological history path to the estimated in situ state based on the $K_{0}$ value measured on site. The approach path followed was that for unit $A_{3}$ in Figure 4, even if the sample was from $B_{2(a)}$. It also failed on a pre-existing fissure. The Brick prediction of the initial starting point in situ was inconsistent with the assumed stress state of the test data and the initial state had to be moved, as indicated in Figure 9. In these cases Brick gives very poor predictions of the stress path directions and the shear strengths predicted are about $50 \mathrm{kPa}$ lower than those measured in the laboratory, which is typical of Brick in such scenarios. M3SKH gives a reasonable prediction of the stress path direction in compression, not so good in extension, but again the problem is the strengths, which are once more much too high, with the stress paths again being cut off at $4 \%$ in compression and $2 \%$ in extension.

\section{Comparisons between numerical predictions and triaxial test results using an improved M3SKH model}

In Figure 10 the same test as in Figure 6 (sample 26.3iUC) is again compared with predictions, but in this case M3SKH was improved significantly by including anisotropy. These predictions were made using a single element in the M3SKH code rather than the full ICFEP code. In Figure 10(a) only the elastic component of the strains has been assumed to be anisotropic, with a ratio $E_{\mathrm{h}} / E_{\mathrm{v}}$ of 2 . The effect is not limited simply to the very small elastic bubble, as there are elastic components of the strains throughout the test. In Figure 10(b) the same ratio has been applied also to the plastic component of strain, and it is interesting that this actually makes little difference to the stress 


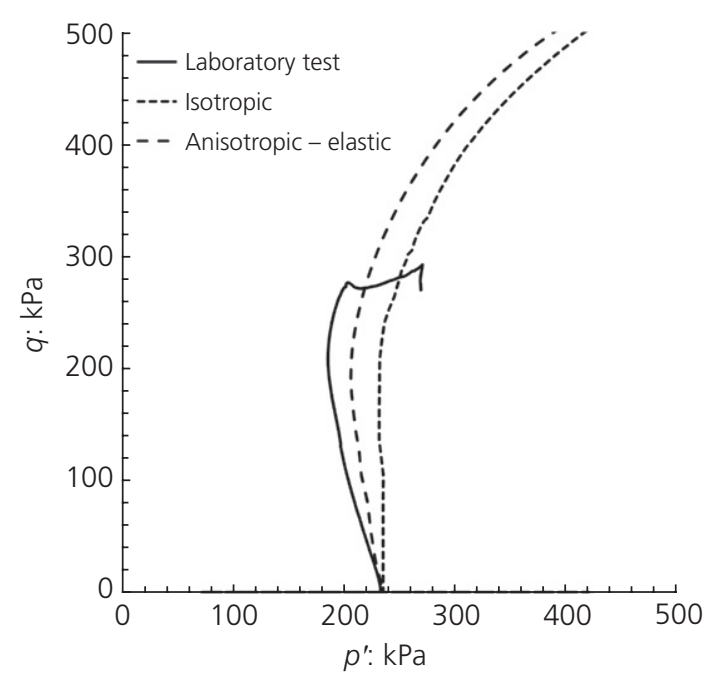

(a)

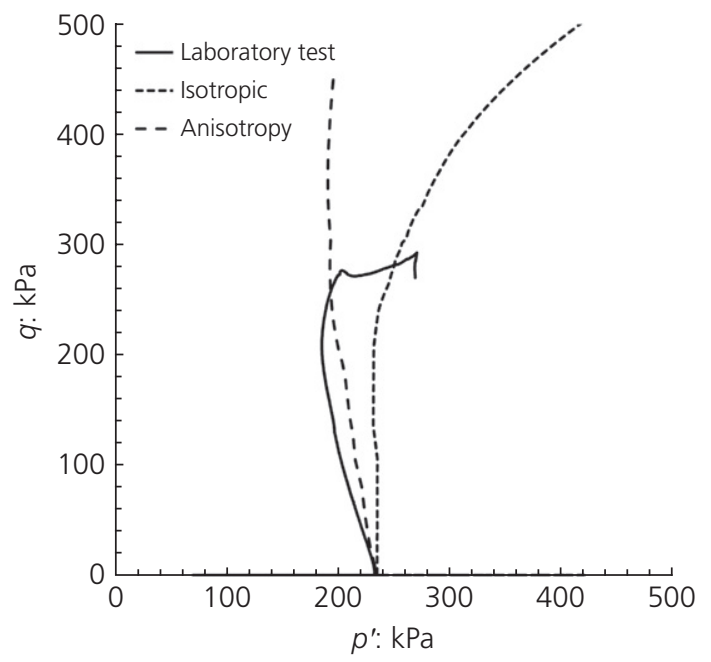

(b)

Figure 10. Effects of anisotropy on computed stress path: (a) anisotropy applied to elastic region only; (b) anisotropy applied to elastic and plastic regions

path direction. This may explain why some authors (e.g. Gasparre et al., 2007b) have been able to predict the stress path direction of London Clay by using elastic stiffness anisotropy, even if the test data they compare with travel well outside Y1. Again the strengths predicted by M3SKH are completely wrong.

Attempts were made to limit the strengths predicted by M3SKH by using the modified version of 3SKH of Baudet and Stallebrass (2004), which accounts for the effects of soil structure. By collapsing the larger state boundary surface of the structured soil immediately on reaching a specific stress ratio, the strength could be limited, although this artificial use of rapid destructuring to mimic the effects of strain localisation in stiff clays was not intended by the authors. In any case it was found that the predictions of the stress paths at larger strains were poor. Instead, the simpler approach of applying a limiting $q / p^{\prime}$ of 1.25 was applied to M3SKH. This ratio was based on the data of Gasparre et al. (2007b) and was found could adequately be used to represent both samples failing on new localisations formed during shearing and those failing on pre-existing fissures. The only complication with this procedure is that, when the limiting stress ratio is reached, the state boundary surface, history surface and Y1 surface need to shrink instantly to the current stress point, as illustrated in Figure 11. However, adopting this procedure, together with the simple representation of the stiffness anisotropy, very good predictions of both the stress path and strength could be obtained with M3SKH, as shown in Figure 12(a). This sample, $25 \mathrm{gUC}$, had followed the short geological history for unit $B_{2 \text { (a) }}$ in Figure 4 and it failed on a new strain localisation formed during the test. Figure 12(b) gives predictions for sample 11.7iUC from unit $B_{2(\mathrm{c})}$ which had been sheared from a simple

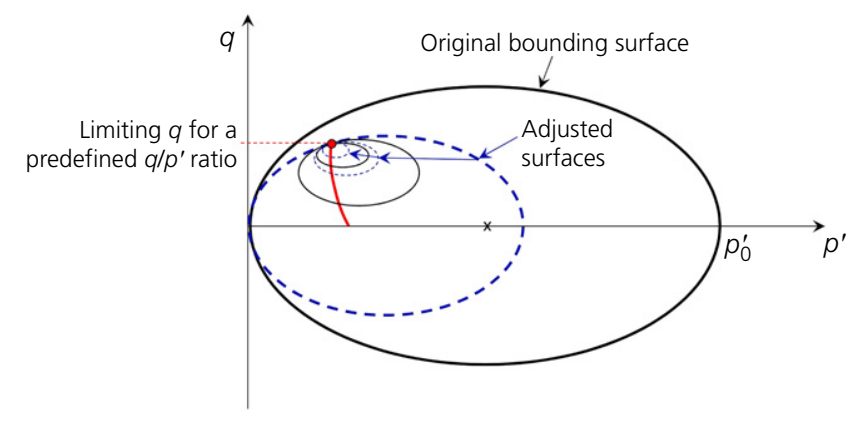

Figure 11. Schematic representation of adjustment of the surfaces when strength limit is applied

isotropic state and which again failed on a new localisation. In this case the anisotropy did not much affect the stress path, but the strength termination is effective. Sample 23.6iUC in Figure 12(c) had been compressed isotropically to high stress levels. It was a $38 \mathrm{~mm}$ sample that also failed on a new localisation. The predictions of M3SKH with stiffness anisotropy and strength curtailment are again reasonable.

\section{Conclusions}

Even if there were a number of sophisticated constitutive models for natural clays at the time when this research was undertaken, none was capable of modelling two important aspects of its behaviour, the anisotropy of small strain stiffness arising from the natural microstructure and the curtailment of strength arising either from the fissures that form part of the natural macro-fabric or from strain localisation on new shear surfaces formed during loading. Comparisons between 

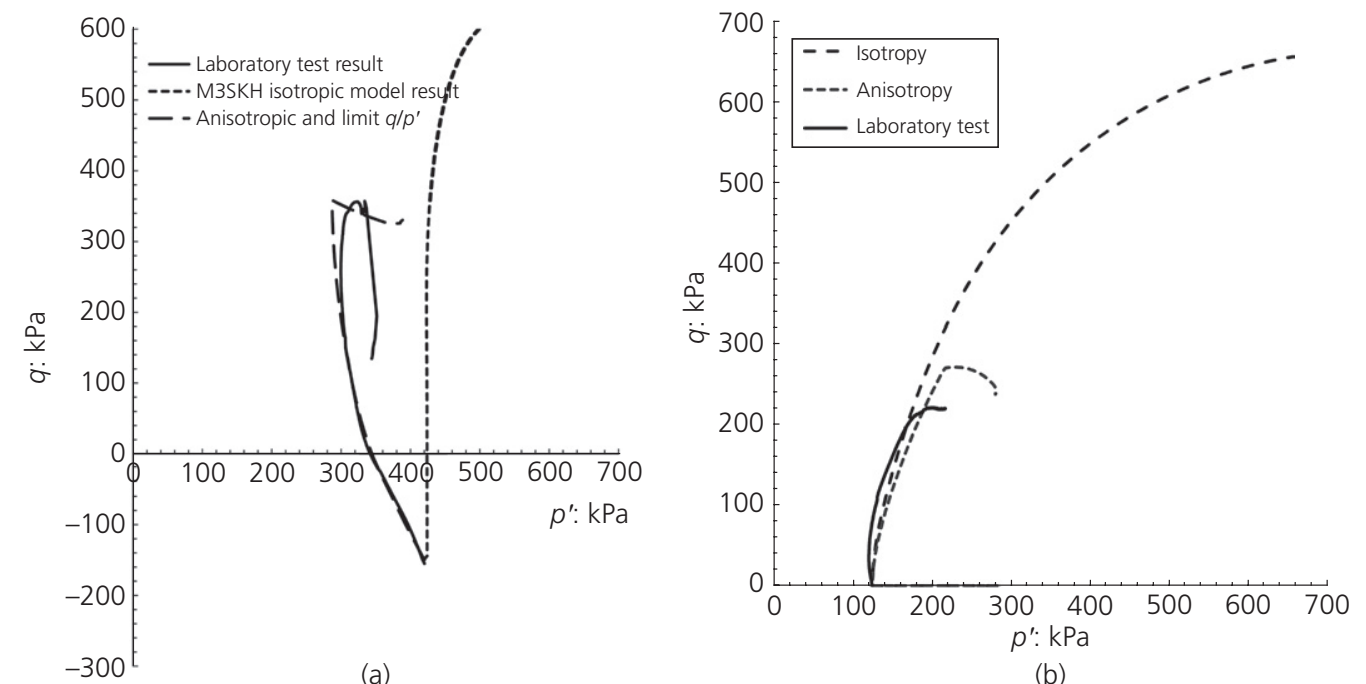

(b)

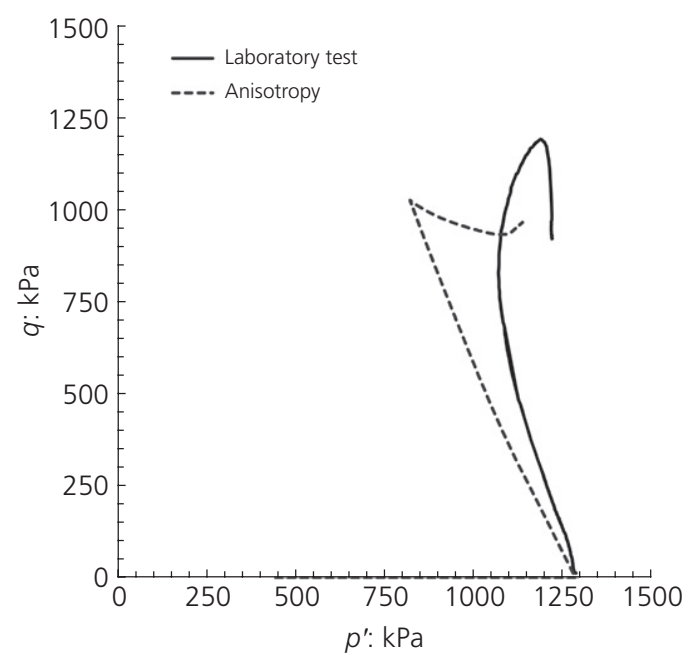

(c)

Figure 12. Effects of limiting $q / p^{\prime}$ ratio by adjusting size of bounding surface: (a) stress path for test $25 \mathrm{gUC}$; (b) stress path for test 11.7iUC; (c) stress path for test 23.6iUC (all the anisotropic tests with strength curtailment)

high-quality triaxial tests and predictions from two existing constitutive models have highlighted their deficiencies. Although the Brick model is found to predict the shear strength fairly well, a major limitation of the Brick model was found to be the prediction of the stress path in cases where the initial state is not close to isotropic. The M3SKH provided both poor predictions of strength and stress paths, but could be modified relatively simply to incorporate the anisotropy of small strain stiffness and a strength limit, after which it then gave very good agreement with the laboratory data.

Since this research work, Ellison et al. (2010, 2012) have introduced anisotropy into the Brick model and they have shown marked improvement of the prediction from the revised formulation. Ellison and co-workers also found that the Brick model occasionally produced unrealistic 'kinks' in the stress path when a complex recent strain history has changed the location of the short strings relative to the current strain points.

\section{Acknowledgements}

The authors are grateful for the financial assistance of the Royal Society Industry Fellowship scheme and Arup Geotechnics, which allowed the first author to spend 3 years part-time at Imperial College, and to Dr A. Gasparre for permission to use the triaxial test data. The authors are also very 
grateful for the advice and support provided by Professor Lidija Zdravkovic in the use of ICFEP program and general soil constitutive modelling aspects of this research and also to Dr Béatrice Baudet for her advice.

\section{REFERENCES}

Al-Tabbaa A and Muir Wood D (1989) An experimental based 'bubble' model for clay. In Proceedings of International Conference on Numerical Models in Geomechanics (Pietruskzczak A and Pande GN (eds)). Balkema, Rotterdam, Netherlands, pp. 91-99.

Atkinson JH (2000) Non-linear soil stiffness in routine design. Géotechnique 50(5): 487-508.

Atkinson JH, Richardson D and Stallebrass SE (1990) Effect of stress history on the stiffness of overconsolidated soil. Géotechnique 40(4): 531-540.

Baudet BA and Stallebrass SE (2004) A constitutive model for structured clays. Géotechnique 54(4): 269-278.

Burland JB (1990) On the compressibility and shear strength of natural clays. Géotechnique 40(3): 329-378.

Chandler RJ, Willis MR, Hamilton PS and Andreou I (1998) Tectonic shear zones in the London Clay formation. Géotechnique 48(2): 257-270.

Clayton CRI and Heymann G (2001) Stiffness of geomaterials at very small strains. Géotechnique 51(3): 245-255.

Dafalias YF and Herrmann (1980) A bounding surface soil plasticity model. International Symposium on Soils under Cyclic and Transient Loading, Swansea, UK, vol. 1, pp. 335-345.

Desai CS, Somasundaram S and Frantziskonis G (1986) A hierarchical approach for constitutive modelling of geologic materials. International Journal of Numerical and Analytical Methods in Geomechanics 10(3): 225-257.

Einav I and Puzrin AM (2004) Pressure-dependent elasticity and energy conservation in elastoplastic models for soils. Journal of Geotechnical and Geoenvironmental Engineering 130(1): 81-92.

Ellison KC, Soga K and Yeow H (2010) Numerical modeling of hollow cylinder tests in London Clay. Proceedings of International Symposium on Deformation Characteristics of Geomaterials, Seoul, Korea, pp. 1074-1081.

Ellison KC, Soga K and Simpson B (2012) A strain space soil model with evolving stiffness anisotropy. Géotechnique 62(7): 627-641.

Gajo A and Muir Wood D (2001) A new approach to anisotropic, bounding surface plasticity; general formulation and simulations of and simulations of natural and reconstituted clay behaviour. International Journal of Numerical and Analytical Methods in Geomechanics 25(3): 207-241.

Gasparre A (2005) Advanced Laboratory Characterisation of London Clay. $\mathrm{PhD}$ thesis, Imperial College London, London, UK.

Gasparre A, Nishimura S, Anh-Minh N, Coop MR and Jardine RJ (2007a) The stiffness of natural London Clay.
Symposium in print on stiff clays. Géotechnique 57(2): 33-47.

Gasparre A, Nishimura S, Coop MR and Jardine RJ (2007b) The influence of structure on the behaviour of London Clay, symposium in print on stiff clays. Géotechnique 57(2): 19-31.

Graham J and Houlsby GT (1983) Anisotropic elasticity of a natural clay. Géotechnique 33(2): 165-180.

Grammatikopoulou A, Zdravkovic L and Potts DM (2006) General formulation of two kinematic hardening constitutive models with a smooth elasto-plastic transition. International Journal of Geomechanics, ASCE 6(5): 291-302.

Hardin BO and Black WL (1966) Sand stiffness under various triaxial stresses. Journal of the Soil Mechanics and Foundations Division, ASCE 92(SM2): 27-42.

Hight DW, Gasparre A, Nishimura S, Minh NA, Jardine RJ and Coop MR (2007) Characteristics of London Clay from terminal 5 site at Heathrow airport. Géotechnique 57(1): 3-18.

Houlsby GT, Amorosi A and Rojas E (2005) Elastic moduli of soils dependent on pressure: a hyperelastic formulation. Géotechnique 55(5): 383-392.

Jardine RJ (1995) One perspective on the pre-failure deformation characteristics of some geomaterials. Keynote lecture. Proceedings of the International Symposium on Pre-Failure Deformation Characteristics of Geomaterials, Hokkaido, Japan, vol. II, pp. 885-886.

Jardine RJ, Potts DM, Fourie AB and Burland JB (1986) Studies of the influence of non-linear stress-strain characteristics in soil-structure interaction. Géotechnique 36(3): 377-396. Jovicic V, Coop MR and Simpson B (2006) Interpretation and modelling of deformation characteristics of a stiff North Sea clay. Canadian Geotechnical Journal 43(4): 341-354.

Kavvadas M and Amorosi A (2000) A constitutive model for structured soils. Géotechnique 50(3): 263-273.

Koskinen M, Karstunen M and Wheeler SJ (2002) Modelling destructuration and anisotropy of a natural soft clay. Proceedings of the 5th European Conference on Numerical Methods in Geotechnical Engineering, Paris, France, pp. 11-19.

Lade PV and Nelson RB (1987) Modelling the elastic behaviour of granular materials. Int. J. Numerical and Analytical Methods in Geomechs 11(5): 521-542.

Mroz Z, Norris VA and Zienkiewicz OC (1978) An anisotropic hardening model for soils and its application to cyclic loading. International Journal for Numerical and Analytical Methods in Geomechanics, vol. 2, pp. 203-221.

Nishimura S, Anh-Minh N and Jardine RJ (2007) Shear strength anisotropy of natural London Clay. Symposium in print on stiff clays. Géotechnique 57(2): 49-62.

Pantelidou H and Simpson B (2007) Geotechnical variation of London Clay across central London. Géotechnique 62(1): $101-112$.

Potts DM and Zdravkovic L (1999) Finite Element Analysis in Geotechnical Engineering: Theory. Thomas Telford, London, UK. 
Rampello S, Viggiani GMB and Amorosi A (1997) Small-strain stiffness of reconstituted clay compressed along constant triaxial effective stress ratio paths. Géotechnique 47(3): 475-489.

Rouainia M and Muir Wood D (2000) A kinematic hardening constitutive model for natural clays with loss of structure. Géotechnique 50(2): 153-164.

Simpson B (1992) 32nd Rankine Lecture. Retaining structures - displacement and design. Géotechnique 42(4): 539-576.

Simpson B, O'Riordan NJ and Croft DD (1979) A computer model for the analysis of ground movements in London Clay. Géotechnique 29(2): 149-175.

Sorensen KK, Baudet BA and Simpson B (2007) Influence of structure on the time-dependent behaviour of a stiff sedimentary clay. Géotechnique 62(1): 113-124.
Stallebrass SE and Taylor RN (1997) The development and evaluation of a constitutive model for the prediction of ground movements in overconsolidated clay. Géotechnique 47(2): 235-353.

Viggiani G and Atkinson JH (1995) Stiffness of fine-grained soil as very small strain. Géotechnique 45(1): 149-154.

Whittle AJ (1993) Evaluation of a constitutive model for overconsolidated clays. Géotechnique 43(2): 289-313.

Wroth CP and Houlsby GT (1985) Soil mechanics - property characterisation and analysis procedures. Proceedings of the 11th International Conference on Soil Mechanics, San Francisco, vol. 1, pp. 1-55.

Zytynski M, Randolph MF, Nova R and Wroth CP (1978) On modelling the unloading-reloading behaviour of soils. International Journal of Numerical and Analytical Methods in Geomechanics 2(1): 87-94. 